Review Article

\title{
Effects of Aging on the Color and Translucency of Monolithic Translucent Y-TZP Ceramics: A Systematic Review and Meta-Analysis of In Vitro Studies
}

\author{
Chang-yuan Zhang, ${ }^{1}$ Check Agingu, ${ }^{1}$ James Kit Hon Tsoi $\mathbb{D},{ }^{2}$ and Hao Yu $\mathbb{D}{ }^{1,3}$ \\ ${ }^{1}$ Fujian Key Laboratory of Oral Diseases \& Fujian Provincial Engineering Research Center of Oral Biomaterial \& Stomatological Key \\ Laboratory of Fujian College and University, School and Hospital of Stomatology, Fujian Medical University, Fuzhou 350002, China \\ ${ }^{2}$ Faculty of Dentistry, University of Hong Kong, Hong Kong SAR, China \\ ${ }^{3}$ Department of Applied Prosthodontics, Graduate School of Biomedical Sciences, Nagasaki University, Nagasaki, Japan
}

Correspondence should be addressed to Hao Yu; haoyu-cn@hotmail.com

Received 14 September 2020; Revised 8 December 2020; Accepted 11 January 2021; Published 27 January 2021

Academic Editor: Fernanda Faot

Copyright (c) 2021 Chang-yuan Zhang et al. This is an open access article distributed under the Creative Commons Attribution License, which permits unrestricted use, distribution, and reproduction in any medium, provided the original work is properly cited.

Background. Monolithic restorations made of translucent yttria-stabilized tetragonal zirconia polycrystal (Y-TZP) have become popular over the past few decades. However, whether aging affects the color and translucency of monolithic translucent Y-TZP is unclear. Objective. The aim of this systematic review and meta-analysis of in vitro studies was to evaluate the effects of aging on the color and translucency of monolithic translucent Y-TZP ceramics. Materials and Methods. This systematic review/ meta-analysis was reported according to the PRISMA statement and registered in the OSF registries (https://osf.io/5qjmu). Four databases including Medline via the PubMed, Embase, and Web of Science databases and the Cochrane Library were searched using no publication year and language limits. The last search was executed on November 20, 2020. In vitro studies comparing the translucency and/or color of monolithic translucent Y-TZP ceramics before and after simulated aging were selected. Meta-analyses were performed using Review Manager software (version 5.3, Cochrane Collaboration, Oxford, UK) with random-effects models at a significance level of 0.05 . A risk-of-bias assessment was also performed for the included studies. Results. Of the 188 potentially relevant studies, 13 were included in the systematic review. The hydrothermal aging duration ranged from 1 to $100 \mathrm{~h}$ at relatively similar temperatures $\left(\sim 134^{\circ} \mathrm{C}\right)$. In the general metaanalyses, the aged Y-TZP ceramics exhibited similar translucency parameter (TP), $\mathrm{L}^{*}$, and $\mathrm{b}^{*}$ values compared with the nonaged controls $(P=.73, P=.49$, and $P=.62$, respectively). Moreover, there was a significant difference between the aged and nonaged Y-TZP ceramics in the $\mathrm{a}^{*}$ value $(P=.03 ; \mathrm{MD}=-0.26 ; 95 \% \mathrm{CI}=-0.51$ to -0.02$)$, favoring the nonaged $\mathrm{Y}$-TZP ceramics. The subgroup analyses showed that the duration of aging contributed to changes in the translucency and color of the Y-TZP ceramics. Conclusions. The optical properties of monolithic translucent Y-TZP ceramics were stable after hydrothermal aging at $134^{\circ} \mathrm{C}$ and $0.2 \mathrm{MPa}$ for $\leq 20 \mathrm{~h}$. Moreover, clinically unacceptable changes in the translucency and color of monolithic translucent Y-TZP ceramics were found after hydrothermal aging for $>20 \mathrm{~h}$.

\section{Introduction}

The popularity of dental zirconia has increased in recent decades because of its excellent mechanical characteristics, biocompatibility, and acceptable esthetic properties $[1,2]$. A questionnaire-based survey regarding the selection of dental ceramic materials reported that dental zirconia was one of the top choices for both anterior (layered) and posterior (monolithic) restorations [3].
At ambient pressure, zirconia can exhibit 3 allotropic crystal phase structures: a monoclinic phase $(m)$ from room temperature to $1170^{\circ} \mathrm{C}$, a tetragonal phase $(t)$ from $1170^{\circ} \mathrm{C}$ to $2370^{\circ} \mathrm{C}$, and a cubic phase $(c)$ above $2370^{\circ} \mathrm{C}$ to its melting point at $2715^{\circ} \mathrm{C}$ and boiling point of $4300^{\circ} \mathrm{C}[4,5]$. To stabilize the $t$ and $c$ phases of zirconia at room temperature, the addition of different amount of stabilizing oxides, such as yttria $\left(\mathrm{Y}_{2} \mathrm{O}_{3}\right)$, to pure zirconia crystals is essential and well studied $[2,4,6]$. In particular, $t$ phase zirconia is useful in 
dentistry because of its strength $[2,6]$. Therefore, yttriastabilized zirconia polycrystal (Y-TZP) has been widely used as a framework for fixed dental prostheses (FDPs) and monolithic restorations [7]. To date, there are three generations of Y-TZP ceramics $\left(1^{\text {st }}, 2^{\text {nd }}\right.$, and $3^{\text {rd }}$ generations $)$ in dentistry [2]. First-generation Y-TZP ceramics are $3 \mathrm{~mol} \%$ (5.2 wt\%) Y-TZP (3Y-TZP) containing $0.25 \mathrm{wt} \%$ alumina, which are highly opaque. Second-generation Y-TZP ceramics are refined by reducing the concentration of alumina $(<0.05 \mathrm{wt} \%)$ and sintering at a higher temperature $\left(\sim 1450^{\circ} \mathrm{C}\right)$ of 3Y-TZP [2]. To further reduce opacity, $3^{\text {rd }}$ generation $\mathrm{Y}$ TZP ceramics are refined by increasing the yttria content to 4 and $5 \mathrm{~mol} \%$ (4Y-TZP and 5Y-TZP) to stabilize the $c$ phase content $(>25 \%)[2]$. Both $2^{\text {nd }}$ and $3^{\text {rd }}$ generations of Y-TZP ceramics are considered translucent and are indicated for posterior and/or anterior monolithic crowns and FDPs $[2,8]$.

Although $c$ phase zirconia does not undergo stressinduced transformation [8], the $2^{\text {nd }}$ and $3^{\text {rd }}$ generations $\mathrm{Y}$ TZP still have $t$ phase so that $t$-to- $m$ phase transformation will eventually be activated and accelerated when the YTZP ceramic is subjected to a humid environment with constant temperature changes, which is usually referred to as aging or low-temperature degradation (LTD) [9-13]. Evidence of aging has been observed in zirconia used in hip implants [14]. In fact, the mechanism of aging has been described using different theories and speculations $[15,16]$. For example, water vapor has been proposed to attack the $\mathrm{Zr}-\mathrm{O}$ bond and be incorporated into zirconia grains by filling oxygen vacancies; then, aging proceeds into the bulk material and jeopardizes the molecular and mechanical properties of Y-TZP ceramics $[17,18]$. On the other hand, Lange et al. [19] proposed that water reacts with $\mathrm{Y}_{2} \mathrm{O}_{3}$ to form clusters rich in $\mathrm{Y}(\mathrm{OH})_{3}$, which leads to the depletion of the stabilizer in the surrounding zirconia grains and induces aging. This mechanism has also been supported by a recent study [20].

Despite the fact that various aging mechanisms have been proposed, the effects of aging on Y-TZP ceramics are still being studied and reported in the literature [13, 21-23]. The simulated aging of Y-TZP ceramics has commonly been performed by steam autoclave at $120^{\circ} \mathrm{C}$ to $140^{\circ} \mathrm{C}[16,24-27]$. A recent systematic review concluded that hydrothermal aging promoted LTD, as shown by the $t$-to- $m$ phase transformation, and it negatively influenced the flexural strength of Y-TZP ceramics [18]. Moreover, the influences of aging on the surface roughness, surface microhardness, and fracture toughness of Y-TZP ceramics have been previously reported [9, 28-33].

Apart from mechanical properties, optical properties, including color and translucency, are critical for the longterm success of ceramic restorations, especially monolithic restorations [27, 34-36]. However, very limited information concerning the effects of aging on the optical properties of monolithic translucent Y-TZP ceramics $\left(2^{\text {nd }}\right.$ and $3^{\text {rd }}$ generations) is available. Han et al. [6] reported that autoclaving Y-TZP did not change its color, whereas other treatments such as ultraviolet and gamma irradiation changed the color of Y-TZP. Rafael et al. [37] reported significant differences in the lightness, chroma, and hue of Y-TZP ceramics in all groups after aging. In contrast, other studies have reported that Y-TZP ceramics can be considered color stable after a stimulated aging process $[38,39]$. In addition to the color, efforts have also been made to investigate the effects of aging on the translucency of monolithic translucent Y-TZP ceramics. Current studies in the literature have shown that the translucency of Y-TZP ceramics is reduced $[25,40]$ or remains unchanged [41] after aging.

Theoretically, Y-TZP ceramic aging may lead to increased surface roughness and pigment breakdown, jeopardizing the esthetic outcome and stability of ceramic restorations [25]. The effects of aging on the color and translucency of monolithic zirconia were reviewed by Papageorgiou-Kyrana et al. [42]. However, no systematic review or meta-analysis has been performed in this field. Therefore, this systematic review and meta-analysis aimed to evaluate the effects of aging on the translucency and color of monolithic translucent Y-TZP ceramics.

\section{Material and Methods}

This systematic review and meta-analysis was performed according to the Preferred Reporting Items for Systematic Reviews and Meta-Analyses (PRISMA) statement [43] and registered in the OSF registries (https://osf.io/5qjmu). A systematic electronic literature search was conducted in Medline via PubMed, Embase, Web of Science (ISI-Web of Knowledge), and Cochrane Library with no publication year and language limits. The search terms and their combinations used in the literature search are listed in Supplemental Table 1. The last search was executed on November 20, 2020. The PICO questions were defined as follows: P: population-monolithic translucent Y-TZP ceramics; I: intervention-Y-TZP ceramics subjected to aging; $\mathrm{C}$ : control-Y-TZP ceramics not subjected to aging; $\mathrm{O}$ : outcome-an evaluation of color and translucency changes of Y-TZP ceramics; and S: study designs-in vitro studies. The primary evaluated outcome was the translucency of monolithic translucent zirconia, and the secondary evaluated outcome was the color of monolithic translucent zirconia.

Articles that met the following inclusion criteria were included: (1) studies that evaluated the effect of aging on the translucency and/or color of monolithic translucent YTZP ceramics and (2) studies that used translucency and/or color measurements according to ISO/TR 28642:2016 [44]. Articles meeting one or more of the following criteria were excluded: (1) study materials other than monolithic translucent Y-TZP ceramics; (2) reviews, protocols, clinical guidelines, and editorial letters; and (3) studies not using hydrothermal aging [33]. Two reviewers (C.Z. and A.C.) independently performed the literature searches and the study selection. Any disagreements were resolved by discussion or by consultation with another reviewer (H.Y.) [33]. The reference lists of all the selected articles were manually reviewed, and the full texts of potentially related studies were examined [45]. Lastly, manual searches were conducted in the following principal periodicals specific to the area of study: Journal of Prosthetic Dentistry, Journal of Dental Research, Journal of Dentistry, Operative Dentistry, Clinical Oral Investigations, Journal of Oral Rehabilitation, 


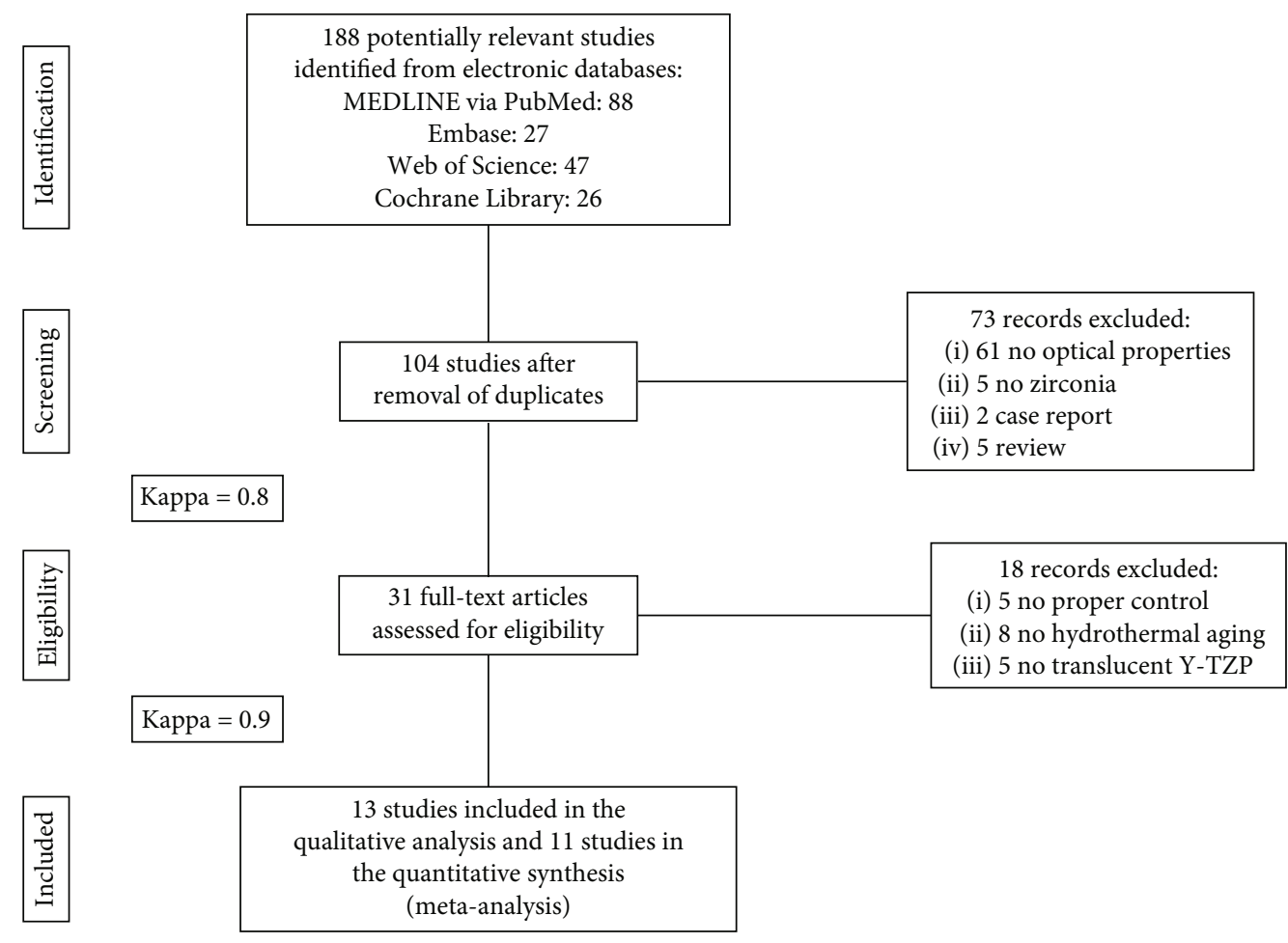

FIgURE 1: Flow diagram of study selection according to the PRISMA statement. PRISMA: Preferred Reporting Items for Systematic Reviews and Meta-Analyses.

International Journal of Prosthodontics, Journal of Prosthodontic Research, Dental Materials Journal, and Journal of Prosthodontics.

A protocol for data extraction was defined and evaluated by 2 reviewers (C.Z. and A.C.) [33]. The following data were extracted from the included studies: demographic information (e.g., authors, publication year, and publication journal and title), the materials tested, the aging protocol, the mean and standard deviation of translucency and/or color, the sample size, and the evaluation methods.

The risk-of-bias assessment was based on a protocol adapted from previous systematic reviews [46, 47]. Briefly, the following parameters were used for the quality assessment: clearly specified aging protocol, sample size calculation, specimen randomization, adequate statistical analysis, ceramic sintering followed the manufacturers' instructions, and tests executed by a single-blinded operator [33]. If a parameter is reported, the study received a "Y"; if the information was missing, the study received an "N." Studies that included 1 or 2 "Y" items were classified as having a high risk of bias, 3 or 4 " $Y$ " items as a medium risk of bias, and 5 to 6 "Y" items as a low risk of bias [33].

For the meta-analysis, studies that did not present data on the translucency parameter (TP) and/or Commission Internationale de L'Éclairage (CIE) $\mathrm{L}^{*}, \mathrm{a}^{*}$, and $\mathrm{b}^{*}$ values were excluded. Studies containing the color difference, contrast ratio, and percentage of total transmittance of light were not considered because of insufficient data. For studies that evaluated more than 1 type of ceramic material or 1 aging duration, all the relevant experimental (aged) groups were combined into a single group, and all the relevant control groups were combined into a single control group according to the Cochrane Statistical Guidelines [48]. All analyses were conducted using Review Manager software (version 5.3; Cochrane Collaboration, Oxford, UK) by employing a random-effects model at a significance level of 0.05 . The mean difference (MD) and 95\% confidence interval (CI) were calculated for the included studies. Subgroup analyses were performed to explore the potential causes of heterogeneity, including the type of monolithic translucent Y-TZP material (3Y-TZP vs. 5Y-TZP) and the steam autoclave duration ( $\leq 20 \mathrm{~h}$ vs. $>20 \mathrm{~h}$ ). For the studies included in the subgroup analyses, all the relevant groups were combined into a single subgroup (e.g., 3Y-TZP or 5Y-TZP for the material type) within a given study [48].

\section{Results}

Thirteen studies were included in the systematic review, and 11 studies were included in the meta-analysis (Figure 1). The characteristics of the included studies are presented in Table 1 . The majority of the included studies ( 9 studies) presented a medium risk of bias, while 2 studies presented a high risk of bias and 2 presented a low risk of bias (Table 2).

The included articles were all in English and were published between 2014 and 2020. Of the 13 studies included in the systematic review, 1 study performed color measurements [37], 8 studies performed translucency evaluations $[13,39-41,49-52]$, and 4 studies performed both types of investigations $[22,25,53,54]$. All included studies were laboratory studies measuring the color and/or translucency with a spectrophotometer. All studies included in the meta- 


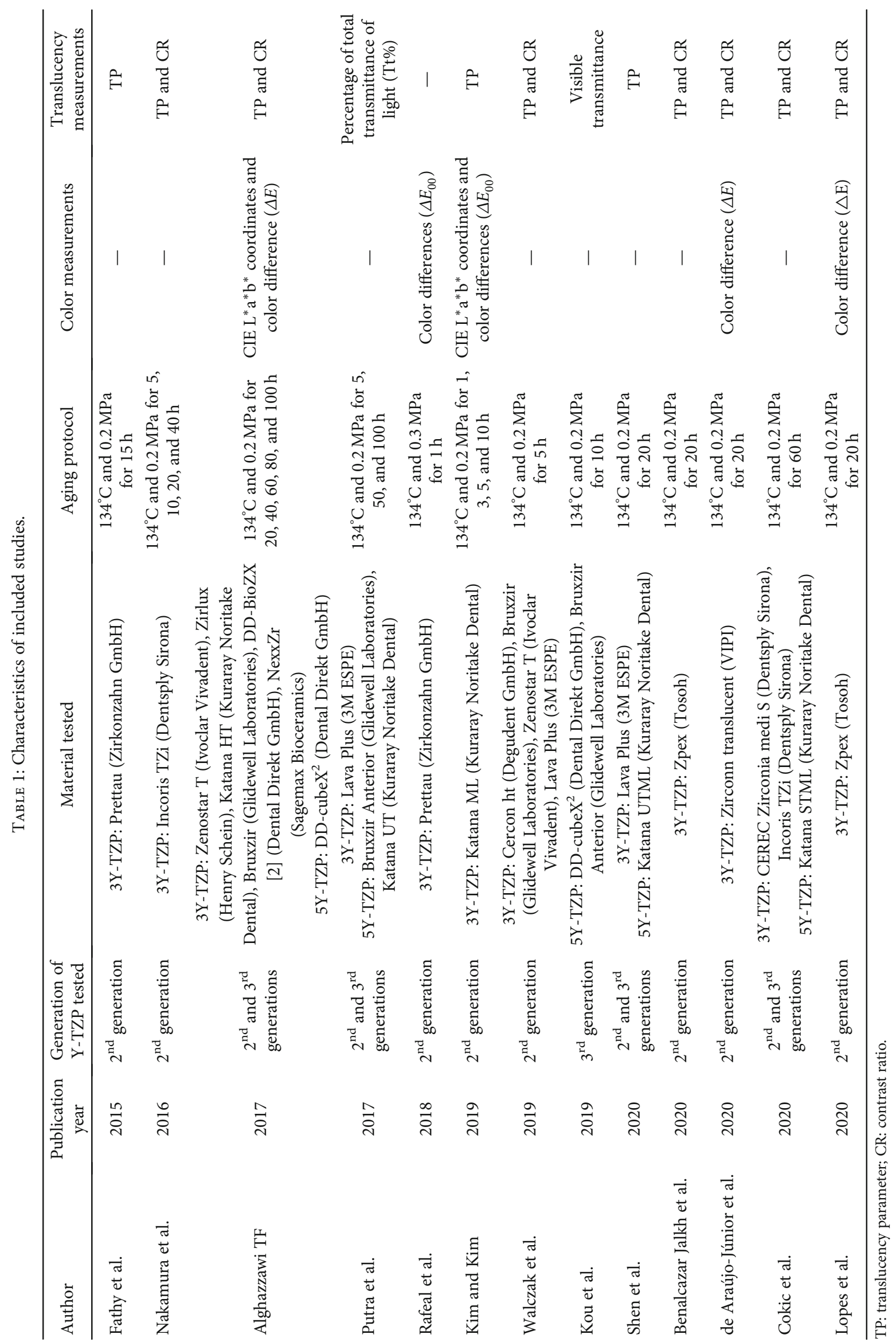


TABLE 2: Risk of bias in included studies.

\begin{tabular}{|c|c|c|c|c|c|c|c|c|}
\hline Author & $\begin{array}{c}\text { Publication } \\
\text { year }\end{array}$ & $\begin{array}{l}\text { Sample size } \\
\text { calculation }\end{array}$ & Randomization & $\begin{array}{l}\text { Aging } \\
\text { protocol }\end{array}$ & $\begin{array}{c}\text { Statistical } \\
\text { analysis }\end{array}$ & $\begin{array}{l}\text { Ceramic } \\
\text { sintering }\end{array}$ & $\begin{array}{c}\text { Blinded } \\
\text { examiner }\end{array}$ & $\begin{array}{c}\text { Risk of } \\
\text { bias }\end{array}$ \\
\hline Fathy et al. & 2015 & $\mathrm{~N}$ & $\mathrm{~N}$ & $\mathrm{Y}$ & $\mathrm{Y}$ & $\mathrm{Y}$ & $\mathrm{N}$ & Medium \\
\hline Nakamura et al. & 2016 & $\mathrm{~N}$ & $\mathrm{~N}$ & $\mathrm{Y}$ & $\mathrm{Y}$ & Y & $\mathrm{N}$ & Medium \\
\hline Alghazzawi TF & 2017 & $\mathrm{~N}$ & $\mathrm{~N}$ & $\mathrm{Y}$ & $\mathrm{Y}$ & Y & $\mathrm{N}$ & Medium \\
\hline Putra et al. & 2017 & $\mathrm{~N}$ & $\mathrm{~N}$ & $\mathrm{Y}$ & $\mathrm{Y}$ & Y & $\mathrm{N}$ & Medium \\
\hline Rafeal et al. & 2018 & $\mathrm{~N}$ & $\mathrm{~N}$ & $\mathrm{Y}$ & $\mathrm{Y}$ & $\mathrm{N}$ & $\mathrm{N}$ & High \\
\hline Kim and Kim & 2019 & $\mathrm{~N}$ & $\mathrm{~N}$ & $\mathrm{Y}$ & $\mathrm{Y}$ & $\mathrm{N}$ & $\mathrm{N}$ & High \\
\hline Walczak et al. & 2019 & $\mathrm{~N}$ & $\mathrm{~N}$ & $\mathrm{Y}$ & $\mathrm{Y}$ & Y & $\mathrm{N}$ & Medium \\
\hline Kou et al. & 2019 & $\mathrm{~N}$ & $\mathrm{Y}$ & $\mathrm{Y}$ & $\mathrm{Y}$ & $\mathrm{Y}$ & $\mathrm{N}$ & Low \\
\hline Shen et al. & 2020 & $\mathrm{~N}$ & $\mathrm{~N}$ & $\mathrm{Y}$ & $\mathrm{Y}$ & $\mathrm{Y}$ & $\mathrm{N}$ & Medium \\
\hline Benalcazar Jalkh et al. & 2020 & $\mathrm{~N}$ & $\mathrm{Y}$ & $\mathrm{Y}$ & Y & $\mathrm{Y}$ & $\mathrm{N}$ & Low \\
\hline de Araújo-Júnior et al. & 2020 & $\mathrm{~N}$ & $\mathrm{~N}$ & $\mathrm{Y}$ & $\mathrm{Y}$ & Y & $\mathrm{N}$ & Medium \\
\hline Cokic et al. & 2020 & $\mathrm{~N}$ & $\mathrm{~N}$ & $\mathrm{Y}$ & $\mathrm{Y}$ & Y & $\mathrm{N}$ & Medium \\
\hline Lopes et al. & 2020 & $\mathrm{~N}$ & $\mathrm{~N}$ & Y & Y & Y & $\mathrm{N}$ & Medium \\
\hline
\end{tabular}

\begin{tabular}{|c|c|c|c|c|c|c|c|c|c|c|c|c|}
\hline \multirow{2}{*}{ Study or subgroup } & \multicolumn{3}{|c|}{ Nonaged } & \multicolumn{3}{|c|}{ Aged } & \multirow{2}{*}{ Weight } & \multirow{2}{*}{$\begin{array}{c}\text { Mean difference } \\
\text { IV, Random, 95\% CI }\end{array}$} & \multirow{2}{*}{\multicolumn{4}{|c|}{$\begin{array}{c}\text { Mean difference } \\
\text { IV, Random, 95\% CI }\end{array}$}} \\
\hline & Mean & $\mathrm{SD}$ & Total & Mean & $\mathrm{SD}$ & Total & & & & & & \\
\hline Alaghazzawi et al. 2017 & 24.8 & 1.4 & 350 & 18.6 & 1.6 & 350 & $11.2 \%$ & $6.20[5.98,6.42]$ & & & & - \\
\hline Benalcazar Jalkh et al. 2020 & 10.23 & 0.41 & 30 & 15.51 & 0.62 & 30 & $11.2 \%$ & $-5.28[5.55,-5.01]$ & - & & & \\
\hline Cokic et al. 2020 & 24.2 & 1.3 & 14 & 20.3 & 2.1 & 14 & $10.9 \%$ & $3.90[2.61,-5.19]$ & & & & \\
\hline de Araújo-Júnior et al. 2020 & 7.71 & 2.23 & 30 & 8.35 & 2.44 & 30 & $10.9 \%$ & $-0.64[-1.82,0.54]$ & & & & \\
\hline Fathy et al. 2015 & 16.4 & 1.32 & 10 & 13.35 & 1.16 & 10 & $11.0 \%$ & $3.05[1.96,4.14]$ & & & & \\
\hline Kim and Kim. 2019 & 4.81 & 0.22 & 40 & 4.95 & 0.37 & 40 & $11.2 \%$ & $-0.14[-0.27,-0.01]$ & & & & \\
\hline Lopes et al. 2020 & 10.21 & 0.2 & 10 & 15.51 & 0.37 & 10 & $11.2 \%$ & $-5.30[-5.56,-5.04]$ & $\Psi$ & & & \\
\hline Shen et al. 2020 & 10.89 & 0.59 & 120 & 9.68 & 1.13 & 120 & $11.2 \%$ & $1.21[0.98,1.44]$ & & & - & \\
\hline Walczak et al. 2019 & 11.73 & 1.24 & 120 & 10.46 & 1.03 & 120 & $11.2 \%$ & $1.21[0.98,1.56]$ & & & - & \\
\hline Total $(95 \% \mathrm{CI})$ & & & 724 & & & 724 & $100.0 \%$ & $0.46[-2.12,3.05]$ & & & & \\
\hline \multicolumn{13}{|c|}{ Heterogeneity: $\operatorname{tau}^{2}=15.50 ; \mathrm{chi}^{2}=6329.66, \mathrm{df}=8(P<0.00001) ; I^{2}=100 \%$} \\
\hline \multicolumn{9}{|c|}{ Test for overall effect: $Z=0.35(P=0.73)$} & -4 & -2 & 2 & \\
\hline & & & & & & & & & \multicolumn{3}{|c|}{ Favours (aged) Favours (nonaged) } & \\
\hline
\end{tabular}

FIgURE 2: Forest plot summarizing the TP values of aged and nonaged Y-TZP ceramics. CI: confidence interval; SD: standard deviation.

analysis adopted hydrothermal aging according to the ISO 13356:2015 [55]. The simulated aging time ranged from 1 to $100 \mathrm{~h}$ at relatively similar temperatures $\left(\sim 134^{\circ} \mathrm{C}\right)$.

The results of the general meta-analysis on translucency (Figure 2) showed no significant difference in the TP value between the nonaged and aged Y-TZP $(P=.73$; mean difference $(\mathrm{MD})=0.46 ; 95 \%$ confidence interval $(\mathrm{CI})=$ -2.12 to 3.05$)$.

The results of the general meta-analysis on the $\mathrm{L}^{*}$ values showed no significant difference in the $\mathrm{L}^{*}$ value between the nonaged and aged Y-TZP $(P=.49 ; \mathrm{MD}=-1.75 ; 95 \% \mathrm{CI}=$ -3.25 to 6.75 ) (Figure 3 ). In the general meta-analysis of $a^{*}$ values, the results showed a significant difference in the $a^{*}$ value between the nonaged and aged Y-TZP $(P=.03 ; \quad \mathrm{MD}=-0.26 ; 95 \% \mathrm{CI}=-0.51$ to -0.02$)$, favoring the nonaged Y-TZP (Figure 4). In the general metaanalysis of $b^{*}$ values (Figure 5), no significant difference in the $b^{*}$ value between the nonaged and aged Y-TZP was found $(P=.62 ; \mathrm{MD}=0.40 ; 95 \% \mathrm{CI}=-1.17$ to 1.97$)$.
Subgroup analyses considering the steam autoclave duration $(\leq 20 \mathrm{~h}$ vs. $>20 \mathrm{~h}$ ) were performed on the translucency and CIE L*a*b* coordinate data (Supplemental Figures 1, 2,3 , and 4 ). The results revealed that the steam autoclave duration contributed to the changes in the translucency and color of the aged Y-TZP ceramics $(P$ all $<.05)$. When the aging duration was $\leq 20 \mathrm{~h}$, no significant differences in the $\mathrm{TP}, \mathrm{L}^{*}$, and $\mathrm{b}^{*}$ values were found between aged and nonaged Y-TZP ceramics $(P$ all $>.05)$. However, when the aging duration was $>20 \mathrm{~h}$, significant differences in the TP, $L^{*}$, and $b^{*}$ values were found between the aged and nonaged Y-TZP ceramics $(P$ all $<.05)$. Significantly greater $a^{*}$ values were found in the aged Y-TZP ceramics than the nonaged ones, regardless of the aging duration. Furthermore, a subgroup analysis considering the type of monolithic translucent Y-TZP ceramic (3Y-TZP vs. 5Y-TZP) was performed on the translucency data (Supplemental Figure 5). No significant differences in the TP values were found between the subgroups $(P=.45)$. 


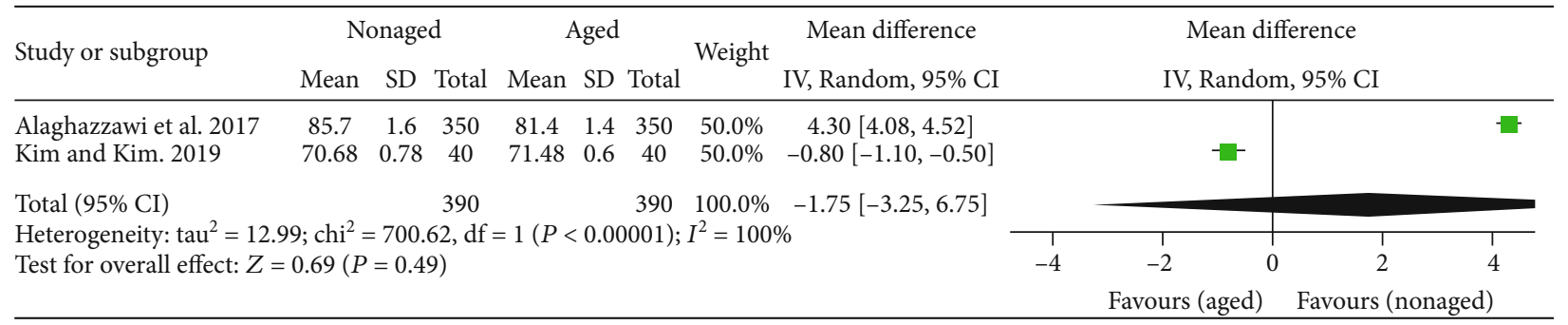

FIGURE 3: Forest plot summarizing the $\mathrm{L}^{*}$ values of aged and nonaged Y-TZP ceramics. CI: confidence interval; SD: standard deviation.

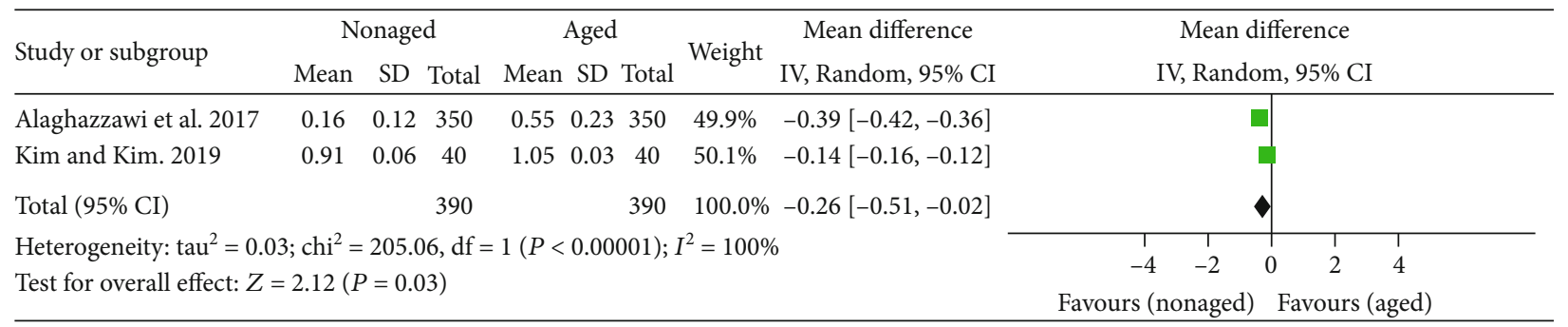

FIgURE 4: Forest plot summarizing the $\mathrm{a}^{*}$ values of aged and nonaged Y-TZP ceramics. CI: confidence interval; SD: standard deviation.

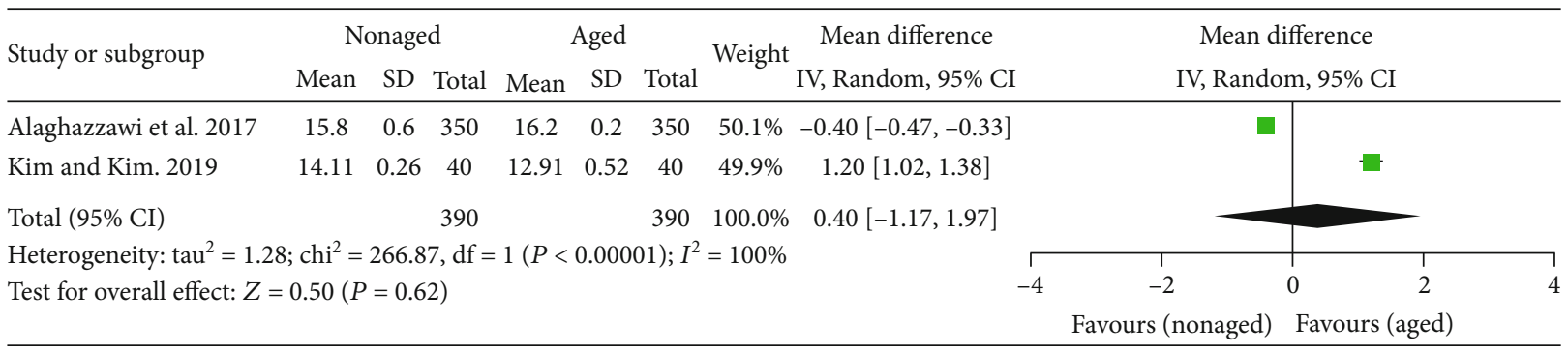

FIGURE 5: Forest plot summarizing the $\mathrm{b}^{*}$ values of aged and nonaged Y-TZP ceramics. CI: confidence interval; SD: standard deviation.

\section{Discussion}

To avoid the chipping of layered restorations, monolithic restorations have been promoted [1]. Monolithic restorations made of translucent Y-TZP ceramics, such as 3Y-TZP and $5 Y-T Z P$, have become popular in recent decades. However, exposing Y-TZP ceramics directly to the oral environment may make them more susceptible to aging [16]. Therefore, this systematic review and meta-analysis was conducted to evaluate the effects of aging on the optical properties of monolithic translucent Y-TZP ceramics and can be considered the first in this study area.

In general, the esthetic outcome of monolithic Y-TZP restorations is mostly dependent on optical properties, including color and translucency. Translucency can be described as the quality of light passing through a material; this aspect is essential to the esthetic performance of dental restorations, which is crucial when selecting a restorative material [27]. The material brand, thickness, and composition (e.g., the yttrium content) have been reported to influence the optical properties of Y-TZP ceramics [56]. Other influencing factors may include the type and quantity of additives, the color shade, the coloring protocol (e.g., preco- lored or colored by immersion in coloring liquids), the presence of $c$ phase content, the sintering temperature and time, and the surface roughness [34-36].

The TP and contrast ratio (CR) have been widely used to describe the translucency of dental materials [27]. Although the CR values were not considered in the present study due to insufficient data, the TP values have been confirmed to highly correlate with the CR values, and they can be used interchangeably [25-27]. The TP values of Y-TZP ceramics remained stable when the duration of hydrothermal aging was $\leq 20 \mathrm{~h}$. However, after hydrothermal aging for $>20 \mathrm{~h}$ (for the included studies, 40 to $100 \mathrm{~h}$ ), the mean $\triangle \mathrm{TP}$ value was 5.05, indicating that the Y-TZP ceramics had become significantly more opaque. Liu et al. [57] concluded that a CR difference $(\triangle \mathrm{CR})$ of 0.07 is the human perception threshold for translucency. Based on the correlation established between the TP and CR values, a $\triangle \mathrm{CR}$ of 0.07 could be transformed into a $\triangle \mathrm{TP}$ value of 2 [58]. Therefore, the translucency changes due to aging detected in the present study might be perceived by visual assessments. The change in translucency during aging is probably associated with the transformation of zirconia from the $t$ phase to the $m$ phase [40]. An increase in the $m$ phase content due to aging causes 
the formation of microcracks and increases the surface porosity, therefore increasing the surface roughness, light scattering, and reflection [11-13]. The coexistence of the $t$ and $m$ phases after aging may also contribute to an increase in the difference in the refractive indices for an incident light beam, thereby decreasing the translucency $[35,59,60]$. The longer the aging duration is, the greater the $t$-to- $m$ phase transformation (greater $m$ phase content). An increase in the $m$ phase content has been proposed to lead to increased opacity due to the abovementioned reasons $[16,61]$.

The color difference $(\Delta E)$ between 2 subjects can be calculated and used to report relative color changes. In dentistry, a $\Delta E$ of 2.7 is considered the threshold for a clinically unacceptable color difference according to ISO/TR 28642:2016 [44]. Apart from $\triangle E$ values, the National Bureau of Standards (NBS) units (NBS units $=\Delta E \times 0.92)$ are also regarded as a means of visual assessment [62]. Significant differences in the $\mathrm{a}^{*}$ values between the aged and nonaged Y-TZP ceramics were found, indicating that the Y-TZP ceramics appeared more reddish (greater $\mathrm{a}^{*}$ ) after aging. According to the meta-analysis, the mean $\Delta \mathrm{L}^{*}, \Delta \mathrm{a}^{*}$, and $\Delta \mathrm{b}^{*}$ values were $-1.75,-0.26$, and 0.40 , respectively. Based on the equation $\Delta E=\sqrt{(\Delta L)^{2}+(\Delta a)^{2}+(\Delta b)^{2}}$ [63], $\Delta E=$ 1.81 , and NBS unit $=1.67$, indicating that the color changes caused by aging might be noticeable. Similar to the TP values, the hydrothermal aging duration contributed to the changes in the CIE $L^{*}, a^{*}$, and $b^{*}$ values. The color (CIE L*, $a^{*}$, and $b^{*}$ values) of the aged monolithic translucent zirconia remained unchanged when the aging duration $\leq 20 \mathrm{~h}$. When the Y-TZP ceramics were aged for more than $20 \mathrm{~h}$ (for the included studies, 40 to $100 \mathrm{~h}$ ), the $\Delta E=5.73$, indicating that the color changes were clinically unacceptable. Theoretically, thermal conditions may have an effect on the coloring pigments added to Y-TZP ceramics, causing pigment breakdown and resulting in color instability [64]. For example, some of the monolithic zirconia consists of minute amount of $\mathrm{Fe}_{2} \mathrm{O}_{3}$ as the pigment [65]. $\mathrm{Fe}_{2} \mathrm{O}_{3}$ has at least three isomorphs $(\alpha, \gamma$, and $\varepsilon$ ) whereas they have different observable band gaps and oxygen valencies, such that $\alpha$ and $\gamma$ are easily interchanged with each other even at room temperature [66]. Nevertheless, the exact mechanism of color instability is not clear and requires further investigation. In addition, the breakdown of colorants could also affect TP which was shown to be related to the changes in lightness and yellowblue coordinates [67]. Thus, color is an important perceptive factor in the determination of the TP, given that TP is determined by the colorimeter/spectrophotometer and the thickness of the specimen tested. In other words, the experimental operating condition is critical and should receive more attention in the literature $[27,50]$.

Although hydrothermal aging is the most common method of accelerated aging, other less aggressive aging methods, such as thermocycling and exposure to ultraviolet light and water spray in a weathering machine, were used in the literature $[23,38]$. Compared with steam autoclave, less aggressive aging methods, such as thermocycling and exposure to ultraviolet light and water spray in a weathering machine, presented less pronounced effects on the optical properties of Y-TZP ceramics. Dikicier et al. [23] reported that aging in a weathering machine for $300 \mathrm{~h}$ is equivalent to 1 year of clinical service. After $200 \mathrm{~h}$ of aging in a weathering machine, the Y-TZP ceramic presented only a minor color change, with a mean $\Delta E$ value of 1.19 . PapageorgiouKyrana et al. [38] concluded that monolithic Y-TZP, either precolored or colored by immersion in staining solutions, can be considered color stable after 5000 thermocycles.

Although sensitivity analyses were conducted, no particular studies were responsible for generating heterogeneity. The high heterogeneity observed in the analyses could be explained by the various brands of test materials and the aging protocols, which may have led to a large change in the aging behavior. The present study was considered to have the following limitations: no subgroup analyses considering the type of Y-TZP ceramic on CIE L*a* $\mathrm{b}^{*}$ coordinate data were performed because of insufficient data. Although the risk of bias assessment was based on previous studies $[46,47]$, the assessment methods may be improved by considering the topic of bias. Moreover, no clinical studies in this field were found; thus, there is weak evidence to support clinical recommendations.

Based on the present findings, the optical properties of monolithic translucent Y-TZP ceramics seemed to be stable after hydrothermal aging at $134^{\circ} \mathrm{C}$ and $0.2 \mathrm{MPa}$ for $\leq 20 \mathrm{~h}$. Clinically unacceptable changes in the translucency and color of monolithic translucent Y-TZP ceramics were found after hydrothermal aging for $>20 \mathrm{~h}$. The general consensus is that $1 \mathrm{~h}$ of autoclave aging is equivalent to 3 to 4 years in vivo [15], although a recent study reported that aging at $134^{\circ} \mathrm{C}$ and $0.2 \mathrm{MPa}$ for $5 \mathrm{~h}$ was considered equivalent to 2 years of aging in vivo [24]. However, it is important to emphasize that in vivo data are needed to correlate the data from laboratory simulations and clinical situations. Therefore, further clinical studies are needed to clarify this hypothesis.

\section{Conclusions}

Within the limitations of this study, the following conclusions may be drawn:

(1) The translucency and color of monolithic translucent Y-TZP ceramics remained stable when the duration of hydrothermal aging was less than $20 \mathrm{~h}$.

(2) Clinically unacceptable changes in the translucency and color of monolithic translucent Y-TZP ceramics were found when the duration of hydrothermal aging was more than $20 \mathrm{~h}$.

\section{Data Availability}

The data supporting the present results are included in this article.

\section{Conflicts of Interest}

The authors declare that they have no conflicts of interest. 


\section{Acknowledgments}

This work was partially supported by the Fujian Provincial Health Technology Project, China (No. 2019-CX-32), and the Startup Fund for Scientific Research, Fujian Medical University, China (No. 2017XQ1112).

\section{Supplementary Materials}

Supplemental Table 1: search terms and combinations used in the literature search. Supplemental Figure 1: forest plot summarizing TP values of aged and nonaged Y-TZP ceramics (subgroup: steam autoclave duration). CI: confidence interval; SD: standard deviation. Supplemental Figure 2: forest plot summarizing $\mathrm{L}^{*}$ values of aged and nonaged Y-TZP ceramics (subgroup: steam autoclave duration). CI: confidence interval; SD: standard deviation. Supplemental Figure 3: forest plot summarizing a* values of aged and nonaged Y-TZP ceramics (subgroup: steam autoclave duration). CI: confidence interval; SD: standard deviation. Supplemental Figure 4: forest plot summarizing $b^{*}$ values of aged and nonaged Y-TZP ceramics (subgroup: steam autoclave duration). CI: confidence interval; SD: standard deviation. Supplemental Figure 5: forest plot summarizing TP values of aged and nonaged Y-TZP ceramics (subgroup: type of Y-TZP ceramic). CI: confidence interval; SD: standard deviation. (Supplementary materials)

\section{References}

[1] C. Agingu, C. Zhang, N. Jiang, H. Cheng, M. Ozcan, and $\mathrm{H}$. Yu, "Intraoral repair of chipped or fractured veneered zirconia crowns and fixed dental prosthesis: clinical guidelines based on literature review," Journal of Adhesion Science and Technology, vol. 32, no. 15, pp. 1711-1723, 2018.

[2] Y. Zhang and B. R. Lawn, "Novel zirconia materials in dentistry," Journal of Dental Research, vol. 97, no. 2, pp. 140$147,2018$.

[3] S. K. Makhija, N. C. Lawson, G. H. Gilbert et al., "Dentist material selection for single-unit crowns: findings from the National Dental Practice-Based Research Network," Journal of Dentistry, vol. 55, pp. 40-47, 2016.

[4] I. Denry and J. Kelly, "State of the art of zirconia for dental applications," Dental Materials, vol. 24, no. 3, pp. 299-307, 2008.

[5] C. Agingu, N.-w. Jiang, H. Cheng, and H. Yu, "Effect of Different Coloring Procedures on the Aging Behavior of Dental Monolithic Zirconia," Journal of Spectroscopy, vol. 2018, Article ID 2137091, 7 pages, 2018.

[6] A. Han, J. K. H. Tsoi, J. P. Matinlinna, Y. Zhang, and Z. Chen, "Effects of different sterilization methods on surface characteristics and biofilm formation on zirconia _in vitro_," Dental Materials, vol. 34, no. 2, pp. 272-281, 2018.

[7] M. Sedda, A. Vichi, M. Carrabba, A. Capperucci, C. Louca, and M. Ferrari, "Influence of coloring procedure on flexural resistance of zirconia blocks," The Journal of Prosthetic Dentistry, vol. 114, no. 1, pp. 98-102, 2015.

[8] F. Zhang, M. Inokoshi, M. Batuk et al., "Strength, toughness and aging stability of highly-translucent Y-TZP ceramics for dental restorations," Dental Materials, vol. 32, no. 12, pp. e327-e337, 2016.
[9] G. K. R. Pereira, C. Muller, V. F. Wandscher, M. P. Rippe, C. J. Kleverlaan, and L. F. Valandro, "Comparison of different lowtemperature aging protocols: its effects on the mechanical behavior of Y-TZP ceramics," Journal of the Mechanical Behavior of Biomedical Materials, vol. 60, pp. 324-330, 2016.

[10] M. Cattani-Lorente, S. S. Scherrer, P. Ammann, M. Jobin, and H. W. A. Wiskott, "Low temperature degradation of a Y-TZP dental ceramic," Acta Biomaterialia, vol. 7, no. 2, pp. 858865, 2011.

[11] T. J. Lucas, N. C. Lawson, G. M. Janowski, and J. O. Burgess, "Effect of grain size on the monoclinic transformation, hardness, roughness, and modulus of aged partially stabilized zirconia," Dental Materials, vol. 31, no. 12, pp. 1487-1492, 2015.

[12] M. Inokoshi, K. Vanmeensel, F. Zhang et al., "Aging resistance of surface-treated dental zirconia," Dental Materials, vol. 31, no. 2, pp. 182-194, 2015.

[13] S. M. Fathy, A. A. El-Fallal, S. A. El-Negoly, and A. B. El Bedawy, "Translucency of monolithic and core zirconia after hydrothermal aging," Acta Biomater Odontol Scand, vol. 1, no. 2-4, pp. 86-92, 2015.

[14] I. C. Clarke, M. Manaka, D. D. Green et al., "Current Status Of Zirconia Used in Total Hip Implants," The Journal of Bone and Joint Surgery-American Volume, vol. 85, pp. 73-84, 2003.

[15] S. Ramesh, K. Y. S. Lee, and C. Y. Tan, "A review on the hydrothermal ageing behaviour of Y-TZP ceramics," Ceramics International, vol. 44, no. 17, pp. 20620-20634, 2018.

[16] V. Lughi and V. Sergo, "Low temperature degradation -agingof zirconia: a critical review of the relevant aspects in dentistry," Dental Materials, vol. 26, no. 8, pp. 807-820, 2010.

[17] G. M. De Souza, A. Zykus, R. R. Ghahnavyeh, S. K. Lawrence, and D. F. Bahr, "Effect of accelerated aging on dental zirconiabased materials," Journal of the Mechanical Behavior of Biomedical Materials, vol. 65, pp. 256-263, 2017.

[18] G. K. R. Pereira, A. B. Venturini, T. Silvestri et al., "Lowtemperature degradation of Y-TZP ceramics: a systematic review and meta- analysis," Journal of the Mechanical Behavior of Biomedical Materials, vol. 55, pp. 151-163, 2015.

[19] F. F. Lange, G. L. Dunlop, and B. I. Davis, "Degradation during aging of transformation-toughened $\mathrm{ZrO} 2-\mathrm{Y} 2 \mathrm{O} 3$ materials at 250oC," Journal of the American Ceramic Society, vol. 69, no. 3, pp. 237-240, 1986.

[20] P. Pandoleon, E. Kontonasaki, N. Kantiranis et al., "Aging of 3Y-TZP dental zirconia and yttrium depletion," Dental Materials, vol. 33, no. 11, pp. e385-e392, 2017.

[21] P. E. Spyropoulou, P. Kamposiora, G. Eliades, G. Papavasiliou, M. E. Razzoog, and S. C. Bayne, "Cyclic loading effect on color stability of unshaded versus shaded zirconia," Journal of Esthetic and Restorative Dentistry, vol. 28, no. 2, pp. 77-84, 2016.

[22] H. K. Kim and S. H. Kim, "Effect of hydrothermal aging on the optical properties of precolored dental monolithic zirconia ceramics," The Journal of Prosthetic Dentistry, vol. 121, no. 4, pp. 676-682, 2019.

[23] S. Dikicier, S. Ayyildiz, J. Ozen, and C. Sipahi, "Effect of varying core thicknesses and artificial aging on the color difference of different all-ceramic materials," Acta Odontologica Scandinavica, vol. 72, no. 8, pp. 623-629, 2014.

[24] M. Cattani-Lorente, S. Durual, M. Amez-Droz, H. W. A. Wiskott, and S. S. Scherrer, "Hydrothermal degradation of a 3Y-TZP translucent dental ceramic: A comparison of 
numerical predictions with experimental data after 2 years of aging," Dental Materials, vol. 32, no. 3, pp. 394-402, 2016.

[25] T. F. Alghazzawi, "The effect of extended aging on the optical properties of different zirconia materials," Journal of Prosthodontic Research, vol. 61, no. 3, pp. 305-314, 2017.

[26] B. Yu, J. S. Ahn, and Y. K. Lee, "Measurement of translucency of tooth enamel and dentin," Acta Odontologica Scandinavica, vol. 67, no. 1, pp. 57-64, 2009.

[27] W. M. Johnston, "Review of translucency determinations and applications to dental materials," Journal of Esthetic and Restorative Dentistry, vol. 26, no. 4, pp. 217-223, 2014.

[28] K. Harada, A. Shinya, H. Gomi, Y. Hatano, A. Shinya, and A. J. Raigrodski, "Effect of accelerated aging on the fracture toughness of zirconias," The Journal of Prosthetic Dentistry, vol. 115, no. 2, pp. 215-223, 2016.

[29] Y. A. Mota, C. Cotes, R. F. Carvalho et al., "Monoclinic phase transformation and mechanical durability of zirconia ceramic after fatigue and autoclave aging," Journal of Biomedical Materials Research. Part B, Applied Biomaterials, vol. 105, no. 7, pp. 1972-1977, 2017.

[30] L. F. Guilardi, G. K. R. Pereira, A. Gundel, M. P. Rippe, and L. F. Valandro, "Surface micro-morphology, phase transformation, and mechanical reliability of ground and aged monolithic zirconia ceramic," Journal of the Mechanical Behavior of Biomedical Materials, vol. 65, pp. 849-856, 2017.

[31] P. A. Pinto, G. Colas, T. Filleter, and G. M. De Souza, "Surface and mechanical characterization of dental yttria-stabilized tetragonal zirconia polycrystals (3Y-TZP) after different aging processes," Microscopy and Microanalysis, vol. 22, no. 6, pp. 1179-1188, 2016.

[32] T. J. Lucas, N. C. Lawson, G. M. Janowski, and J. O. Burgess, "Phase transformation of dental zirconia following artificial aging," Journal of Biomedical Materials Research. Part B, Applied Biomaterials, vol. 103, no. 7, pp. 1519-1523, 2015.

[33] H. Yang, Y. L. Xu, G. Hong, and H. Yu, "Effects of lowtemperature degradation on the surface roughness of yttriastabilized tetragonal zirconia polycrystal ceramics: A systematic review and meta-analysis," The Journal of Prosthetic Dentistry, 2020.

[34] L. Jiang, Y. Liao, Q. Wan, and W. Li, "Effects of sintering temperature and particle size on the translucency of zirconium dioxide dental ceramic," Journal of Materials Science. Materials in Medicine, vol. 22, no. 11, pp. 2429-2435, 2011.

[35] Y. Zhang, "Making yttria-stabilized tetragonal zirconia translucent," Dental Materials, vol. 30, no. 10, pp. 1195-1203, 2014.

[36] B. Stawarczyk, A. Emslander, M. Roos, B. Sener, F. Noack, and C. Keul, "Zirconia ceramics, their contrast ratio and grain size depending on sintering parameters," Dental Materials Journal, vol. 33, no. 5, pp. 591-598, 2014.

[37] C. F. Rafael, P. F. Cesar, M. Fredel, R. de Souza Magini, A. Liebermann, and C. A. M. Volpato, "Impact of laboratory treatment with coloring and fluorescent liquids on the optical properties of zirconia before and after accelerated aging," The Journal of Prosthetic Dentistry, vol. 120, no. 2, pp. 276-281, 2018.

[38] A. Papageorgiou-Kyrana, M. Kokoti, E. Kontonasaki, and P. Koidis, "Evaluation of color stability of preshaded and liquid-shaded monolithic zirconia," The Journal of Prosthetic Dentistry, vol. 119, no. 3, pp. 467-472, 2018.

[39] T. Nakamura, Y. Nakano, H. Usami et al., "Translucency and low-temperature degradation of silica-doped zirconia: A pilot study," Dental Materials Journal, vol. 35, no. 4, pp. 571-577, 2016.

[40] K. Walczak, H. Meißner, U. Range et al., "Translucency of Zirconia Ceramics before and after Artificial Aging," Journal of Prosthodontics, vol. 28, no. 1, pp. e319-e324, 2019.

[41] A. Putra, K. H. Chung, B. D. Flinn et al., "Effect of hydrothermal treatment on light transmission of translucent zirconias," The Journal of Prosthetic Dentistry, vol. 118, no. 3, pp. 422429, 2017.

[42] K. Papageorgiou-Kyrana, M. Fasoula, and E. Kontonasaki, "Translucency of monolithic zirconia after hydrothermal aging: a review of in vitro studies," Journal of Prosthodontics, vol. 29, no. 6, pp. 489-500, 2020.

[43] D. Moher, A. Liberati, J. Tetzlaff, D. G. Altman, and for the PRISMA Group, "Preferred reporting items for systematic reviews and meta-analyses: the PRISMA statement," $B M J$, vol. 339, no. jul21 1, p. b2535, 2009.

[44] International Standard ISO/TR 28642:2016, Dentistry-guidance on colour measurement, Geneva, Switzerland, 2016, 2nd Edition.

[45] H. Yu, Y. H. Chen, H. Cheng, and T. Sawase, "Finish-line designs for ceramic crowns: a systematic review and metaanalysis," The Journal of Prosthetic Dentistry, vol. 122, no. 1, pp. 22-30.e5, 2019.

[46] R. Sarkis-Onofre, J. A. Skupien, M. S. Cenci, R. R. Moraes, and T. Pereira-Cenci, "The role of resin cement on bond strength of glass-fiber posts luted into root canals: a systematic review and meta-analysis of in vitro studies," Operative Dentistry, vol. 39, no. 1, pp. E31-E44, 2014.

[47] H. Yu, M. Ozcan, K. Yoshida, H. Cheng, and T. Sawase, "Bonding to industrial indirect composite blocks: a systematic review and meta- analysis," Dental Materials, vol. 36, no. 1, pp. 119-134, 2020.

[48] J. P. Higgins, J. J. Deeks, and D. G. Altman, "Chapter 16: Special topics in statistics," Cochrane Handbook for Systematic Reviews of Interventions Version 5.1.0. The Cochrane Collaboration, J. P. Higgins and S. Green, Eds., 2011, Available from http://handbook.cochrane.org/.

[49] W. Kou, K. Garbrielsson, A. Borhani, M. Carlborg, and M. M. Thorén, "The effects of artificial aging on high translucent zirconia," Biomaterial Investigations in Dentistry, vol. 6, no. 1, pp. 54-60, 2019.

[50] J. Shen, H. Xie, X. Wu, J. Yang, M. Liao, and C. Chen, "Evaluation of the effect of low-temperature degradation on the translucency and mechanical properties of ultra-transparent 5Y-TZP ceramics," Ceramics International, vol. 46, no. 1, pp. 553-559, 2020.

[51] E. B. B. Jalkh, K. N. Monteiro, P. F. Cesar et al., “Aging resistant ZTA composite for dental applications: Microstructural, optical and mechanical characterization," Dental Materials, vol. 36, no. 9, pp. 1190-1200, 2020.

[52] S. M. Cokic, J. Vleugels, B. Van Meerbeek et al., "Mechanical properties, aging stability and translucency of speed-sintered zirconia for chairside restorations," Dental Materials, vol. 36, no. 7, pp. 959-972, 2020.

[53] E. N. S. de Araújo-Júnior, E. T. P. Bergamo, T. M. B. Campos et al., "Hydrothermal degradation methods affect the properties and phase transformation depth of translucent zirconia," Journal of the Mechanical Behavior of Biomedical Materials, vol. 112, p. 104021, 2020. 
[54] A. C. O. Lopes, P. G. Coelho, L. Witek et al., "Microstructural, mechanical, and optical characterization of an experimental aging-resistant zirconia-toughened alumina (ZTA) composite," Dental Materials, vol. 36, no. 12, pp. e365-e374, 2020.

[55] International Standard ISO 13356:2015, Implants for surgery. Ceramic materials based on yttria-stabilized tetragonal zirconia (Y-TZP), Geneva, Switzerland, 2015, 3rd Edition.

[56] S. Kurtulmus-Yilmaz and M. Ulusoy, "Comparison of the translucency of shaded zirconia all-ceramic systems," J Adv Prosthodont, vol. 6, no. 5, pp. 415-422, 2014.

[57] M. C. Liu, S. A. Aquilino, P. S. Lund et al., "Human perception of dental porcelain translucency correlated to spectrophotometric measurements," Journal of Prosthodontics, vol. 19, no. 3, pp. 187-193, 2010.

[58] Y. K. Lee, "Criteria for clinical translucency evaluation of direct esthetic restorative materials," Restor Dent Endod, vol. 41, no. 3, pp. 159-166, 2016.

[59] E. A. McLaren and D. A. Terry, "CAD/CAM systems, materials, and clinical guidelines for all-ceramic crowns and fixed partial dentures," The Compendium of Continuing Education in Dentistry, vol. 23, pp. 637-647, 2002.

[60] M. J. Heffernan, S. A. Aquilino, A. M. Diaz-Arnold, D. R. Haselton, C. M. Stanford, and M. A. Vargas, "Relative translucency of six all-ceramic systems. Part I: core materials," The Journal of Prosthetic Dentistry, vol. 88, no. 1, pp. 4-9, 2002.

[61] M. T. Hernandez, J. R. Jurado, P. Duran, and J. L. G. Fierro, "Subeutectoid degradation of yttria-stabilized tetragonal zirconia polycrystal and ceria-doped yttria-stabilized tetragonal zirconia polycrystal ceramics," Journal of the American Ceramic Society, vol. 74, no. 6, pp. 1254-1258, 1991.

[62] T. Koksal and I. Dikbas, "Color stability of different denture teeth materials against various staining agents," Dental Materials Journal, vol. 27, no. 1, pp. 139-144, 2008.

[63] N. Jiang, C. Zhang, C. Agingu, T. Attin, H. Cheng, and H. Yu, "Comparison of whitening dentifrices on the effectiveness of in-office tooth bleaching: a double-blind randomized controlled clinical trial," Operative Dentistry, vol. 44, no. 2, pp. 138-145, 2019.

[64] F. Gonuldas, K. Yilmaz, and C. Ozturk, "The effect of repeated firings on the color change and surface roughness of dental ceramics," J Adv Prosthodont, vol. 6, no. 4, pp. 309-316, 2014.

[65] T. A. Sulaiman, A. A. Abdulmajeed, K. Shahramian, and L. Lassila, "Effect of different treatments on the flexural strength of fully versus partially stabilized monolithic zirconia," The Journal of Prosthetic Dentistry, vol. 118, no. 2, pp. 216-220, 2017.

[66] M. de Ridder, P. C. van de Ven, R. G. van Welzenis et al., "Growth of Iron Oxide on Yttria-Stabilized Zirconia by Atomic Layer Deposition," The Journal of Physical Chemistry $B$, vol. 106, no. 51, pp. 13146-13153, 2002.

[67] C. Gasparik, A. V. Burde, A. G. Grecu, I. Chiorean, D. Dudea, and M. E. Badea, "The influence of color parameters on the translucency of ceramic material," J Optoelectron Advanced Materials, vol. 9, pp. 241-242, 2015. 